\title{
Thermal effect on current gains of an AlGaAs/GaAs heterostructure-emitter bipolar transistor
}

\author{
H. B. Lo and E. S. Yang \\ Department of Electrical and Electronic Engineering, The University of Hong Kong, Hong Kong, China \\ Y. F. Yang ${ }^{\text {a) }}$ \\ Global Communication Semiconductors, Incorporated, Torrance, California 90505
}

(Received 23 November 1998; accepted for publication 29 January 1999)

The temperature effect on current gains is presented for an $\mathrm{AlGaAs} / \mathrm{GaAs}$ heterostructure-emitter bipolar transistor (HEBT). Experimental results show that the HEBT has much less temperature sensitivity in current gain than a heterojunction bipolar transistor. The current gains for the HEBT are almost constant with the substrate temperature at a high current regime. This indicates that the HEBT could be a good candidate for power applications. (C) 1999 American Institute of Physics. [S0003-6951(99)04312-0]

Recent development indicates that GaAs heterojunction bipolar transistors (HBTs) will play an increasing role in present and future microwave and millimeter-wave power applications. ${ }^{1}$ Although AlGaAs/GaAs power HBTs have been widely used, ${ }^{2}$ the issue of the power $\mathrm{AlGaAs} / \mathrm{GaAs}$ HBT is that the current gain decreases with the increase of temperature which results in the negative differential resistance. The main reason of gain degradation for AlGaAs/ GaAs HBTs is the low valence band offset $\left(\Delta E_{v}\right)$ at the heterojunction, ${ }^{3}$ assuming that the hole current injected from the base to the emitter is diffusion limited. If, however, the mechanism of the hole current is dominated by thermionic emission rather than diffusion, the temperature dependence of current gain will be modified. The heterostructure-emitter bipolar transistor (HEBT), with separate electron injection and hole confinement, ${ }^{4}$ has been proposed by taking advantage of both special features of heterojunction and homojunction. It can effectively eliminate the emitter potential spike and offer low offset voltage. ${ }^{5}$ The heterostructure emitter can also slow down the degradation caused by base dopant outdiffusion which improves the device's reliability. ${ }^{6}$ Moreover, HEBT structure is like a poly-Si BJT in which the hole current injected from the base to the emitter is likely to be dominated by thermionic emission at high temperature. ${ }^{7}$ Since the thermionic emission current has a temperature dependence of $\sim T^{2}$ plus an exponential factor, the current gain can become less dependent on the junction temperature. It was recently demonstrated that the current gain of an $\mathrm{InGaP} /$ GaAs HEBT increase along with the increase of temperature were observed due to thermionic emission current dominant. ${ }^{8}$ In this letter, we present experimental results of the temperature dependence of the current gain for AlGaAs/ GaAs HEBTs. It is shown that the current gain of the HEBT is much less sensitive to temperature variation than that of a normal AlGaAs/GaAs HBT. The current gain is found to be almost constant with increasing temperature for the HEBT at the high current regime.
AlGaAs/GaAs HEBTs were grown by molecular beam epitaxy on a Sl GaAs substrate. The HEBT structure consists of a $5000 \AA \mathrm{GaAs}$ subcollector layer $\left(n=3 \times 10^{18} \mathrm{~cm}^{-3}\right)$, a $5000 \AA$ GaAs collector layer $\left(n=1 \times 10^{16} \mathrm{~cm}^{-3}\right)$, a $800 \AA$ GaAs base layer $\left(p=1 \times 10^{19} \mathrm{~cm}^{-3}\right)$, a $300 \AA$ GaAs emitter layer $\left(n=1 \times 10^{17} \mathrm{~cm}^{-3}\right)$, a $500 \AA \mathrm{Al}_{x} \mathrm{Ga}_{1-x}$ As confinement layer $\left(n=3 \times 10^{17} \mathrm{~cm}^{-3}, \quad x=0.3\right)$, a $500 \AA$ $\mathrm{Al}_{x} \mathrm{Ga}_{1-x} \mathrm{As}$ graded layer $\left(n=3 \times 10^{17} \mathrm{~cm}^{-3}, x=0.3-0\right)$, a $1000 \AA$ GaAs emitter cap layer $\left(n=4 \times 10^{18} \mathrm{~cm}^{-3}\right)$, and a $600 \AA$ graded $\operatorname{In}_{x} \mathrm{Ga}_{1-x}$ As ( $x$ from 0 to 0.5 ) contact layer $\left(n=5 \times 10^{18} \mathrm{~cm}^{-3}\right)$. Si and Be were used as $n$ - and $p$-type dopants, respectively.

HEBTs were fabricated using the conventional mesa structure. A thin depleted AlGaAs ledge was employed as a passivation layer on the extrinsic base surface to reduce the surface recombination current. Figure 1 shows the cross section of a typical HEBT. A large emitter size of $40 \times 100 \mu \mathrm{m}^{2}$ was used to further reduce the periphery effect on the current gain. After the HEBTs were fabricated, the devices were packaged in a chip carrier. Gummel plots at a base-collector bias of $0 \mathrm{~V}$ were measured at the temperature range from 25 to $175{ }^{\circ} \mathrm{C}$. Since the base collector was biased at $0 \mathrm{~V}$, the device junction temperature was assumed to be the same as the substrate temperature, $T_{\text {sub }}$.

A typical Gummel plot of the HEBT at room tempera-

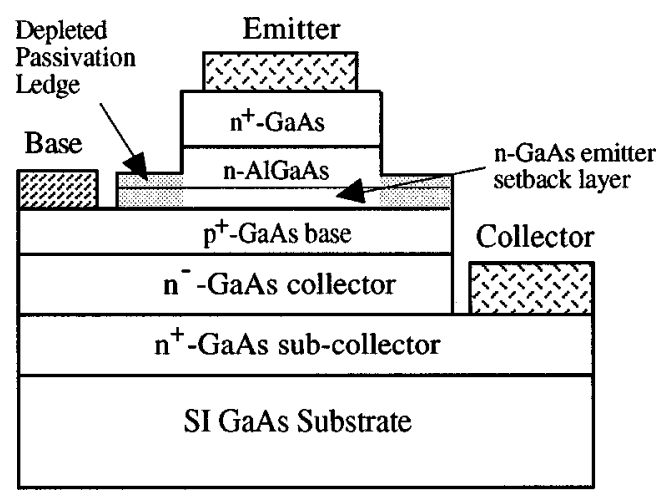

FIG. 1. Cross section of the AlGaAs/GaAs HEBT. 


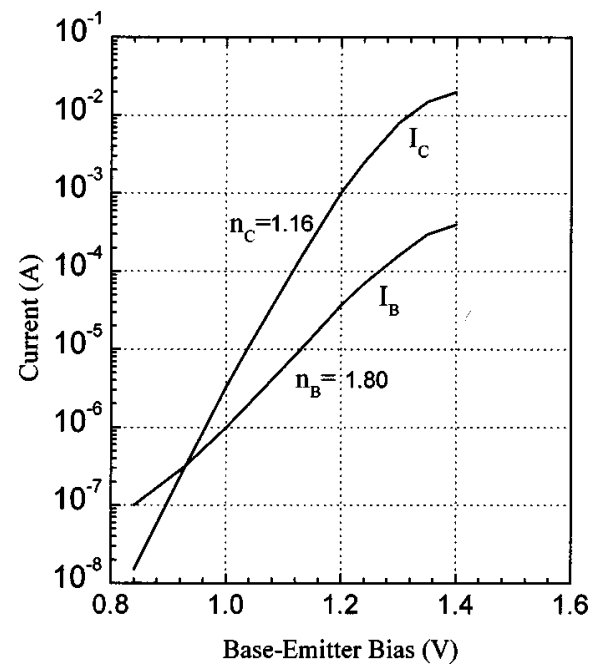

FIG. 2. Gummel plot of the HEBT at room temperature.

ture is shown in Fig. 2. A current gain $(\beta)$ of 52 at room temperature was obtained. The ideality factors of collector and base currents are 1.16 and 1.80, respectively. Figure 4 shows the current gain versus collector current at various substrate temperatures for the AlGaAs/GaAs HEBT. The current gain is almost constant at $T_{\text {sub }}<100{ }^{\circ} \mathrm{C}$ and becomes slightly lower at $T_{\text {sub }}>100{ }^{\circ} \mathrm{C}$. It is noted that $\beta$ remains the same at the high current regime. Figure 3 shows the current gain, normalized by its value at room temperature, as a function of the substrate temperatures at the collector current densities $\left(J_{c}\right)$ of $250 \mathrm{~A} / \mathrm{cm}^{2}$. The experimental data from Ref. 9 are also shown in Fig. 4 for comparison. The current gain of the HEBT at $T_{\text {sub }}$ of $175^{\circ} \mathrm{C}$ is reduced by only $10 \%$ for $J_{c}$ of $250 \mathrm{~A} / \mathrm{cm}^{2}$. In comparison, $\beta$ for the HBT decreases by $65 \%$ at a higher $J_{c}$ and its drop is even more pronounced at low $J_{c} \cdot{ }^{3,9}$ It is noted that the current gain of the HEBT shown in Fig. 4 is at a $J_{c}$ about a hundred times lower than that of the HBT. ${ }^{9}$ If the gain was obtained at a higher $J_{c}$, the drop in gain for the HEBT would have been even less significant. It is evident that less temperature sensitivity in the

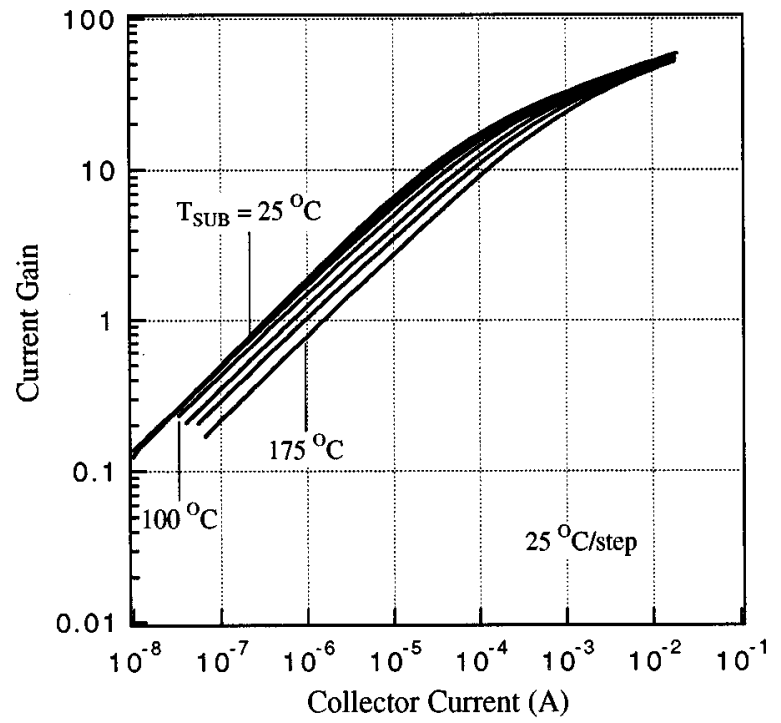

FIG. 3. Current gain vs collector current for the HEBT at various substrate

temperatures.
Downloaded 13 Nov 2006 to 147.8.21.97. Redistribution subject to AlP license or copyright, see http://apl.aip.org/apl/copyright.jsp

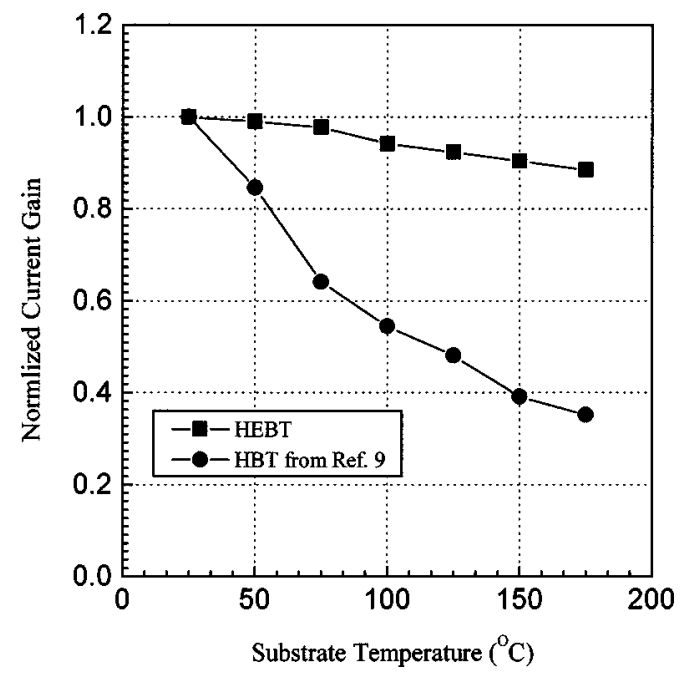

FIG. 4. Normalized current gain vs substrate temperature for the HEBT of this work at $J_{c}=250 \mathrm{~A} / \mathrm{cm}^{2}$ and HBT $J_{c}=2.5 \times 10^{4} \mathrm{~A} / \mathrm{cm}^{2}$ from Ref. 9. The current gain is normalized by its value at room temperature.

current gain was obtained for the HEBT than that of the HBT.

The basic reason for the current gain degradation with temperature in an $\mathrm{AlGaAs} / \mathrm{GaAs} \mathrm{HBT}$ is the small value of $\Delta E_{v}$, based on the assumption of the diffusion dominated hole current. ${ }^{9}$ Since the heterostructure emitter is similar to the poly-Si emitter, the hole injection from the base to the emitter is controlled by thermionic emission at high temperature. ${ }^{7}$ We note that the thermionic emission current has a temperature dependence of $\sim T^{2}$ plus an exponential factor, while the diffusion current has a temperature dependence of $\sim T^{3}$ plus an exponential factor. Hence, the current gain will be less dependent on the junction temperature when the hole current is dominated by thermionic emission. The detailed analysis will be given in a future publication. The above results showed that even though the value of $\Delta E_{v}$ for $\mathrm{AlGaAs} / \mathrm{GaAs}$ material system is lower than that of the $\mathrm{GaInP} / \mathrm{GaAs}$ system, the degree of temperature dependence of $\beta$ for $\mathrm{AlGaAs} / \mathrm{GaAs}$ HEBT is comparable to that of GaInP/GaAs HBT.

In summary, we have reported a significant difference in the temperature dependence of the current gain between HEBTs and HBTs. It is shown that the current gain for the HEBT is much less temperature sensitive and almost constant with increasing junction temperature at a high current level. This suggests that the performance of an HEBT is not obviously degraded at high temperature. If HEBTs are used for power amplifier, the power performance could be improved because the power device often operates at high temperature.

This work was supported by CRCG grant to two of the authors (H.B.L. and E.S.Y.) and RGC Grant No. HKU7057/ $98 \mathrm{E}$.

${ }^{1}$ B. Bayraktaroglu, Proc. IEEE 81, 1762 (1993).

${ }^{2}$ G. B. Gao, H. Morkoc, and M. F. Chang, IEEE Trans. Electron Devices 39, 1987 (1992)

${ }^{3}$ W. Liu, S. K. Fan, T. Henderson, and D. Davito, IEEE Trans. Electron Devices 40, 1351 (1993).

${ }^{4}$ L. F. Luo, H. L. Evans, and E. S. Yang, IEEE Trans. Electron Devices 36, 1844 (1989)

Alicense or copyright, see http://apl.aip.org/apl/copyright.jsp 
${ }^{5}$ W. S. Lour, W. C. Liu, D. F. Guo, and R. C. Liu, Jpn. J. Appl. Phys., Part 1 31, 2388 (1992).

${ }^{6}$ Y. F. Yang, C. C. Hsu, and E. S. Yang, Semicond. Sci. Technol. 10, 339 (1995).

${ }^{7}$ C. C. Ng and E. S. Yang, Tech. Dig. Int. Electron Devices Meet. 32 (1986).
${ }^{8}$ E. S. Yang, Y. F. Yang, C. C. Hsu, H. J. Ou, and H. B. Lo, IEEE Trans. Electron Devices 46, 320 (1999).

${ }^{9}$ W. Liu, E. Beam, III, T. Kim, and A. Khatibzadeh, in Current Trends in Heterojunction Bipolar Transistors, edited by M. F. Chang (World Scientific, Singapore, 1996), pp. 241-301. 